\title{
A comparative study of executive functions among children with attention deficit and hyperactivity disorder and those with learning disabilities
}

\author{
Heba Essam Abou El Wafa*, Soha Abd El Latif Ghobashy and Aya Maged Hamza
}

\begin{abstract}
Background: Both ADHD and learning disorders have been found to be associated with executive dysfunctions; the executive functions' (EFs) construct generally involves a series of components - planning, cognitive flexibility, inhibition, attention control, and verbal and visuo-spatial working memory-that work independently in many ways but are closely related. There were no significant studies comparing both disorders and excluding the drug's effects on executive functions. In our study, we used BDEFS-CA to assess executive functions among a sample of 340 children divided in to four groups: group 1 (100 children), ADHD only; group II (80 children), LD only; group III (60 children), combined ADHD and LD; and group IV (100 children), control group. We included children aged from 6 to 13 of both sexes of average IQ and all had to be drug naive with no sensory impairment or disabling neurological disorder and after their parents' consent.

Results: The results showed that there was significant higher affection of the five executive functions domains in the first three groups more than the fourth control group. Furthermore, the self-restraint (response-inhibition) executive dysfunction was the most commonly affected EF in group I while time management EF and self-regulation and problem solving EF were the most commonly affected EF in the LD group.

Conclusions: Complete executive function profile assessment should be done for children diagnosed with ADHD or learning disability and EF intervention program should be included in the management plan for better outcomes mainly self-restraint EF in case of ADHD and problem solving and self-organization EF in case of learning disabilities
\end{abstract}

Keywords: Executive functions, ADHD, Learning disability

\section{Background}

Both attention deficit hyperactivity disorder ( ADHD) and learning disorders (LD) have been found to be associated with executive dysfunctions; the executive functions' (EFs) construct generally involves a series of components-planning, cognitive flexibility, inhibition, attention control, and verbal and visuo-spatial working memory-that work independently in many ways but are closely related [1].

Neuropsychological studies of executive functions in ADHD found that children and adolescents with ADHD

\footnotetext{
*Correspondence: Heba_essam3@yahoo.com
}

Psychiatry, Alexandria University, Alexandria, Egypt exhibited significant deficits compared to those without ADHD in neuropsychological measures of EFs (inhibitory control, vigilance, planning, verbal and spatial working memory, and cognitive flexibility) [1].

Cognitive deficits particularly impairments in attention and executive functions are considered to be a core part of ADHD (Barkley, 1997) and are thought to play a, major role in the difficult adaptation of ADHD [2]. These dysfunctions have been shown to be independent of psychiatric comorbidity associated with ADHD [2].

According to the Indian Psychiatry Society guidelines, learning difficulty is a mild form where the child has only mild difficulty in particular areas such as reading or

\section{Springer Open}

(0) The Author(s). 2020 Open Access This article is licensed under a Creative Commons Attribution 4.0 International License, which permits use, sharing, adaptation, distribution and reproduction in any medium or format, as long as you give appropriate credit to the original author(s) and the source, provide a link to the Creative Commons licence, and indicate if changes were made. The images or other third party material in this article are included in the article's Creative Commons licence, unless indicated otherwise in a credit line to the material. If material is not included in the article's Creative Commons licence and your intended use is not permitted by statutory regulation or exceeds the permitted use, you will need to obtain permission directly from the copyright holder. To view a copy of this licence, visit http://creativecommons.org/licenses/by/4.0/. 
writing, and on standardized testing of achievements may not be substantially below the expected level, whereas in LD the child has substantial difficulty and is evident on standardized testing, and the difficulty can be overcome to a significant extent by remedial education. These guidelines define learning disability when the child has severe difficulty in particular areas that are evident on standardized test of achievement, and in spite of adequate therapeutic efforts, there may not be any significant improvement. So it is more like a spectrum of increasing severity from learning difficulty to disability [3].

Research has provided numerous indications that specific learning disabilities are associated with working memory impairments; further evidence suggests that these children also experience deficits in central executive functioning. However, relatively few reports exist with regard to impairments of the visual-spatial working memory of children with reading disabilities [4]. Empirical findings on children with specific arithmetic learning disabilities are also available for all three domains of working memory. Here the central executive seems to be particularly impaired [5].

The research reviewed thus far has indicated that EF may influence reading development from preschool throughout the school years. In particular, prereading skills are related to inhibition and cognitive flexibility; word-reading proficiency is related to working memory, inhibition, shifting, updating, and attentional control; and reading comprehension is associated, at the very least, with planning, working memory, and inhibition. These findings are promising and point to the important role of EF in reading acquisition [6].

Recent research suggests that executive function skills, which include monitoring and manipulating information in mind (working memory), suppressing distracting information and unwanted responses (inhibition), and flexible thinking (shifting), play a critical role in the development of mathematics proficiency [7].

Skilled writing is a self-directed activity, which is driven by the goals that writers set for what they want to do and say. To meet these goals, the writer must skillfully and flexibly (i.e., thoughtfully) apply and coordinate a variety of resources, including strategic processes (i.e., mental operations for planning, drafting, and revising), knowledge (e.g., about the topic, the intended audience), and skills (handwriting, spelling, sentence construction). The success of this enterprise rests on careful analysis (e.g., determining the demands of the writing task) as well as decision making and planning (e.g., determining a suitable approach to tackling the writing problem). The entire process places considerable demands on the writer's attention, as it requires simultaneously juggling or coordinating a number of constraints and processes [8].

Although it is known that rating scales and clinical reports of how the person manages everyday tasks are far more sensitive and valid diagnostic indicators than laboratory tests or performance-based tasks of EF, but most of studies done used the laboratory tests, also due to the high comorbidity between ADHD and learning disabilities. There were no significant studies comparing both disorders and excluding the drug's effects on executive functions.

Also in spite of the fact that children with ADHD benefit from working memory training program and the good response of children with reading disorders to executive functions training program, still a very few studies has compared the deficits of executive functions in ADHD and learning disabilities.

Therefore, the objective of our study was to study EF domains affected in ADHD and LD as in spite of progress in understanding ADHD and LD still their relation with EF is not fully elaborated.

\section{Methods \\ Study design: comparative case-control study Study setting}

This study was carried out on children attending the Child and Adolescent Psychiatry Outpatient Clinic - El Hadara University Hospital from May 2016 till December 2017.

The studied children (drug naïve, of normal intelligence, both gender from 6-13 years old) were subjected to:

I) History taking

II) Physical and neurological examination

III) Psychiatric assessment

Using the semi-structured clinical interview Kiddie schedule for affective disorder and schizophrenia (KSADS) which use Diagnostic and Statistical Manual IV ( DSM-IV-TR) criteria for diagnosis [9].

The typical sheet revised by the Alexandria University staff members and applied in El Hadra outpatient clinic was used.

IV) Psychometric assessment:

A) Intelligence quotient (IQ) testing using Stanford binnet test [10].

B) Conner's parent rating form for ADHD severity assessment [11].

C) Barkley Deficits In Executive Functioning Scale-Children and Adolescents (BDEFS-CA) [12].

It was chosen as it provides a valid assessment of executive functioning deficits in daily life activities with an age range of 6 to 17 years. 
Format: Parent-report rating scale (long form). The scale was translated into Arabic version then revised with a jury of 2 psychiatry professors and 1 linguistic specialist; then, it was tested for its reliability regarding Arabic language using Cronbach's alpha

The prototype of (BDEFS-CA) was largely based on an earlier theory of executive functions and its five constructs and their specific adaptive purposes as well as the larger literature on the nature of EF and the rich and lengthy history of descriptions of the symptoms of patients with PFC injuries. Items were developed to reflect inhibition, nonverbal working memory (self-directed sensing, especially visual imagery, sense of time, and time management), verbal working memory (self-directed private speech, verbal contemplation of one's behavior before acting, etc.), emotional-motivational selfregulation (inhibiting emotion, motivating one's self during boring activities, etc.), and reconstitution (planning, problem-solving, and goal-directed inventiveness). According to this theory, the constructs are interactive and serve the overarching purpose of self-organizing behavior across time to prepare for and attain future goals, The scale items focused on problematic symptoms (deficit measurement) rather than on positive or normative EF functioning. The long forms of the BDEFS and the BDEFS-CA are scored by calculating the totals for each of the five scales: Self-Management to Time, SelfOrganization and Problem-Solving, Self-Restraint, SelfMotivation, and Self-Regulation of Emotion. Additionally, the instrument yields a total executive functioning summary score (the total of the five scales), symptom count (number of items rated as occurring often or very often), and an ADHD-executive function index score (with higher score indicating greater likelihood for a clinical diagnosis of ADHD). The short form versions of the BDEFS, intended for quick screening, are scored to yield a total executive functioning summary score. The manuals indicate that results from the BDEFS and BDEFS-CA can be interpreted using four different approaches by (1) interpreting the meaning of each scale separately by identifying high subscale scores and individual items; (2) making normative comparisons (percentile scores based on sex and age group); (3) conducting risk analysis to aid in clinical interpretation with respect to major domains of life activity beyond the BDEFS subscales; and (4) assessing change in patients resulting from treatment. Similar to the BDEFS adult form, reliability of the scale scores is quite satisfactory as evidenced by high internal consistency (Cronbach's alpha ranging from .95 to .97). There is evidence of high test-retest reliability (ranging from .73 to .82 across scales and .82 for the total EF summary score) over a $3-$ 5 -week interval based on a subset of the normative sample. Validity of the scale scores was evident in numerous analyses including factor analyses and correlations with other rating scales of EF. It was also evident in correlations, regression analyses, and group comparisons concerning disorder discrimination and concurrent validity with various measures of functional impairment in major life activities such as family functioning, peer relations, education functioning, community activities, and risk for accidental injuries.

A sample size of 120 children were required to estimate an average difference in executive functions using alpha error $=0.05$ and to provide a study power of $80 \%$. Random sampling was adopted and a total of 340 children were recruited and divided into four groups according to their diagnosis:

Group (I): 100 children diagnosed with attentiondeficit and hyperactivity disorder only.

Group (II): 80 children diagnosed with learning disorder only.

Group (III):60 children diagnosed with combined attention-deficit hyperactivity disorder and learning disabilities disorder.

Group (IV): 100 normal children with matching age, sex, and educational level were taken as a control group.

\section{Results}

Please see Tables 1, 2, 3, and 4 for the results.

\section{Discussion}

\section{Time management EF}

In our work, time management was found to be the second most significantly affected executive function in learning disability affecting $81 \%$ and also in the combined group (group III) affecting $90 \%$ of them.

This is similar to the results of a recent study by Sharfi $\mathrm{K}$ and Rosenblum (December 2016) on executive functions in learning disabilities which concluded that Deficits in initiation and emotional executive functions as well as organization in time abilities and emotional responses to impairments in organizing time. These deficits affected the quality of life of adults with LD [13].

Time management was also significantly affected in the ADHD group in $70 \%$ of children with no significant difference between affection in the three subtypes of ADHD. Also it was significantly affected in the combined group (ADHD and LD) in $81 \%$, similar to the present results of Hosenbocus and Chahal [14] who found that many of the executive dysfunctions are found in children with ADHD including difficulties with priority and time management, planning and organization, initiating and completing tasks in a timely manner, difficulty shifting cognitive set, a high level of procrastination, forgetfulness, and poor working memory [14] (Figs. 1, 2, and 3). 
Table 1 Comparison between the different studied groups according to different executive functions domains

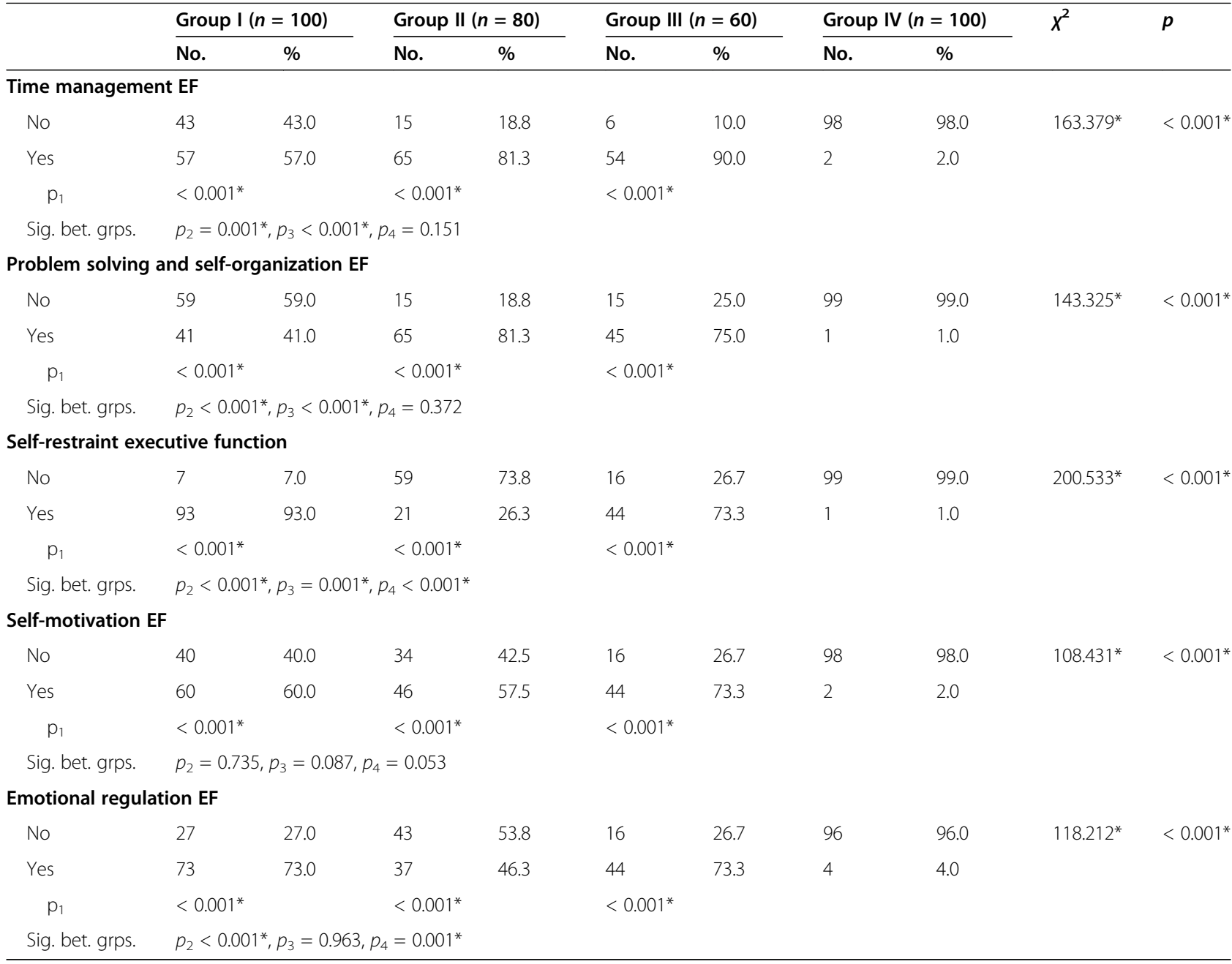

*Statistically significant

Again, time management was significantly associated with other psychiatric comorbidities including most commonly nocturnal enuresis or delayed language was found in $81 \%$ of children, then mood and anxiety disorders in $78 \%$ of children and disruptive behavior disorders in $75 \%$ of children but with no significant association with epilepsy; this might be related to the compound effect of multiple comorbidities adding to a child disturbed mentality and cognition.

\section{Problem solving (self-organization) EF}

In the present study problem solving was the most significantly affected EF in learning disorder group before and after the exclusion of children with other psychiatric comorbidities affecting $81 \%$ of children. Also problem solving was significantly affected in combined group affecting $76 \%$ in agreement with the results found by Mccann [15] using the BRIEF-Parent report that children with dyslexia received significantly higher (reaching more clinical levels) scores than matched controls on the BRIEF Working Memory, Plan/Organize, and Monitor Scales [15].

Also, problem solving was related to other psychiatric comorbidities confirmed by multivariate regression analysis as a risk factor $(\mathrm{OR}=3.98, \mathrm{CI} 1.5-10.2)$ including epilepsy as it was affected in $100 \%$ of the epileptic children followed by disruptive behavior disorders in $67 \%$ of children and mood and anxiety disorders in $62 \%$ of them but no significant association with (nocturnal enuresis or delayed language). Similarly a study using standard performance-based neuropsychological measures (Wechsler Intelligence Scale for Children, Delis Kaplan Executive Functioning System, NIH Toolbox, Test of Everyday Attention for Children) and the Behavior Rating Inventory of Executive Functioning (BRIEF) comprised the multi-method assessment battery. Depending on the measure, $30 \%$ of adolescents with epilepsy had deficits in working memory, $17 \%$ in cognitive flexibility/problem solving, $6 \%$ in inhibition, and $18 \%$ in planning/ organization. Attention was a significant problem for $15 \%$ of adolescents with epilepsy [16]. 
Table 2 Relation between EF and different ADHD subtypes

\begin{tabular}{|c|c|c|c|c|c|c|c|c|}
\hline & \multicolumn{6}{|c|}{ Diagnoses } & \multirow[t]{3}{*}{$x^{2}$} & \multirow[t]{3}{*}{$P$} \\
\hline & \multicolumn{2}{|c|}{ Combined ADHD $(n=45)$} & \multicolumn{2}{|c|}{ Hyperactive ADHD $(n=32)$} & \multicolumn{2}{|c|}{ Inattentive ADHD $(n=23)$} & & \\
\hline & No. & $\%$ & No. & $\%$ & No. & $\%$ & & \\
\hline \multicolumn{9}{|c|}{ Time management EF } \\
\hline No & 20 & 44.4 & 13 & 40.6 & 10 & 43.5 & 0.144 & 0.945 \\
\hline Yes & 25 & 55.6 & 19 & 59.4 & 13 & 56.5 & & \\
\hline \multicolumn{9}{|c|}{ Problem solving and self-organization EF } \\
\hline No & 26 & 57.8 & 21 & 65.6 & 12 & 52.2 & 1.051 & 0.591 \\
\hline Yes & 19 & 42.2 & 11 & 34.4 & 11 & 47.8 & & \\
\hline \multicolumn{9}{|c|}{ Self-restraint executive function } \\
\hline No & 1 & 2.2 & 3 & 9.4 & 3 & 13.0 & 3.388 & ${ }^{M C} p=0.171$ \\
\hline Yes & 44 & 97.8 & 29 & 90.6 & 20 & 87.0 & & \\
\hline \multicolumn{9}{|c|}{ Self-motivation EF } \\
\hline No & 15 & 33.3 & 17 & 53.1 & 8 & 34.8 & 3.391 & 0.184 \\
\hline Yes & 30 & 66.7 & 15 & 46.9 & 15 & 65.2 & & \\
\hline \multicolumn{9}{|c|}{ Emotional regulation EF } \\
\hline No & 13 & 28.9 & 6 & 18.8 & 8 & 34.8 & 1.893 & 0.388 \\
\hline Yes & 32 & 71.1 & 26 & 81.3 & 15 & 65.2 & & \\
\hline
\end{tabular}

Table 3 Relation between other comorbidities and executive function among the studied children

\begin{tabular}{|c|c|c|c|c|c|c|c|c|c|c|c|c|}
\hline & \multicolumn{10}{|c|}{ Comorbidity } & \multirow[t]{3}{*}{$x^{2}$} & \multirow[t]{3}{*}{$P$} \\
\hline & \multicolumn{2}{|c|}{$\begin{array}{l}\text { No comorbidity } \\
(n=203)\end{array}$} & \multicolumn{2}{|c|}{$\begin{array}{l}\text { Nocturnal enuresis and } \\
\text { delayed language }(n=37)\end{array}$} & \multicolumn{2}{|c|}{$\begin{array}{l}\text { Mood or anxiety } \\
\text { comorbidity }(n=37)\end{array}$} & \multicolumn{2}{|c|}{$\begin{array}{l}\text { Disruptive behavior } \\
\text { comorbidity }(n=45)\end{array}$} & \multicolumn{2}{|c|}{$\begin{array}{l}\text { Epilepsy } \\
(n=18)\end{array}$} & & \\
\hline & No. & $\%$ & No. & $\%$ & No. & $\%$ & No. & $\%$ & No. & $\%$ & & \\
\hline \multicolumn{13}{|c|}{ Time management EF } \\
\hline No & 124 & 61.1 & 7 & 18.9 & 8 & 21.6 & 11 & 24.4 & 12 & 66.7 & $49.303^{*}$ & $<0.001^{*}$ \\
\hline Yes & 79 & 38.9 & 30 & 81.1 & 29 & 78.4 & 34 & 75.6 & 6 & 33.3 & & \\
\hline$p_{1}$ & & & $<0.001^{*}$ & & $<0.001^{*}$ & & $<0.001^{*}$ & & 0.641 & & & \\
\hline \multicolumn{13}{|c|}{ Problem solving and self-organization EF } \\
\hline No & 142 & 70.0 & 17 & 45.9 & 14 & 37.8 & 15 & 33.3 & 0 & 0.0 & $54.552^{*}$ & $<0.001^{*}$ \\
\hline Yes & 61 & 30.0 & 20 & 54.1 & 23 & 62.2 & 30 & 66.7 & 18 & 100.0 & & \\
\hline$p_{1}$ & & & $0.005^{*}$ & & $<0.001^{*}$ & & $<0.001^{*}$ & & $<0.0$ & $01^{*}$ & & \\
\hline \multicolumn{13}{|c|}{ Self-restraint executive function } \\
\hline No & 146 & 71.9 & 13 & 35.1 & 12 & 32.4 & 6 & 13.3 & 4 & 22.2 & $75.506^{*}$ & $<0.001^{*}$ \\
\hline Yes & 57 & 28.1 & 24 & 64.9 & 25 & 67.6 & 39 & 86.7 & 14 & 77.8 & & \\
\hline$p_{1}$ & & & $<0.001^{*}$ & & $<0.001^{*}$ & & $<0.001^{*}$ & & $<0.0$ & $01^{*}$ & & \\
\hline \multicolumn{13}{|c|}{ Self-motivation EF } \\
\hline No & 146 & 71.9 & 9 & 24.3 & 13 & 35.1 & 15 & 33.3 & 5 & 27.8 & $57.434^{*}$ & $<0.001^{*}$ \\
\hline Yes & 57 & 28.1 & 28 & 75.7 & 24 & 64.9 & 30 & 66.7 & 13 & 72.2 & & \\
\hline $\mathrm{p}_{1}$ & & & $<0.001^{*}$ & & $<0.001^{*}$ & & $<0.001^{*}$ & & $<0.0$ & $01^{*}$ & & \\
\hline \multicolumn{13}{|c|}{ Emotional regulation EF } \\
\hline No & 168 & 82.8 & 8 & 21.6 & 3 & 8.1 & 1 & 2.2 & 2 & 11.1 & $176.191^{*}$ & $<0.001^{*}$ \\
\hline Yes & 35 & 17.2 & 29 & 78.4 & 34 & 91.9 & 44 & 97.8 & 16 & 88.9 & & \\
\hline $\mathrm{p}_{1}$ & & & $<0.001^{*}$ & & $<0.001^{*}$ & & $<0.001^{*}$ & & $<0.0$ & $01^{*}$ & & \\
\hline
\end{tabular}


Table 4 Relation between accidents and executive function among the studied groups

\begin{tabular}{|c|c|c|c|c|c|c|}
\hline & \multicolumn{4}{|c|}{ Accidents } & \multirow[t]{3}{*}{$x^{2}$} & \multirow[t]{3}{*}{$p$} \\
\hline & \multicolumn{2}{|c|}{$<2(n=324)$} & \multicolumn{2}{|c|}{$\geq 2(n=16)$} & & \\
\hline & No. & $\%$ & No. & $\%$ & & \\
\hline \multicolumn{7}{|c|}{ Time management EF } \\
\hline No & 162 & 50.0 & 0 & 0.0 & $15.281^{*}$ & $<0.001^{*}$ \\
\hline Yes & 162 & 50.0 & 16 & 100.0 & & \\
\hline \multicolumn{7}{|c|}{ Problem solving and self-organization EF } \\
\hline No & 179 & 55.2 & 9 & 56.3 & 0.006 & 0.937 \\
\hline Yes & 145 & 44.8 & 7 & 43.8 & & \\
\hline \multicolumn{7}{|c|}{ Self-restraint executive function } \\
\hline No & 179 & 55.2 & 2 & 12.5 & $11.191^{*}$ & $0.001^{*}$ \\
\hline Yes & 145 & 44.8 & 14 & 87.5 & & \\
\hline \multicolumn{7}{|c|}{ Self-motivation EF } \\
\hline No & 180 & 55.6 & 8 & 50.0 & 0.190 & 0.663 \\
\hline Yes & 144 & 44.4 & 8 & 50.0 & & \\
\hline \multicolumn{7}{|c|}{ Emotional regulation EF } \\
\hline No & 173 & 53.4 & 9 & 56.3 & 0.050 & 0.823 \\
\hline Yes & 151 & 46.6 & 7 & 43.8 & & \\
\hline
\end{tabular}

*Statistically significant

This higher percent we found of problem solving executive dysfunction in case of comorbid epilepsy (100\% compared by other studies (30-50\%) may be explained by the fact that most of epilepsy cases referred to our child psychiatry clinic were of frontal lobe epilepsy subtype. There have been numerous reports of impaired executive functions in this population [17] referred for us for management of behavioral symptoms while other classical epilepsy subtypes are usually referred to our Epilepsy clinic. Also children with comorbid ADHD and epilepsy were not on antiepileptic; untreated epilepsy was proved in a study done on 247 untreated epileptic patient on 2012 to be related to more executive dysfunction (> 50\% of untreated epileptic patients) [18]. Moreover, the fact that our study was done on children so those with early onset epilepsy which was proved by Black [19] on his study on 216 patient which proved that earlier onset was associated with higher executive function deficit.

\section{Self-restraint EF (inhibition)}

In our work, self-restraint was significantly affected in children with ADHD before and after exclusion of children with other comorbid psychiatric disorders affecting 93\% of children (there was no significant difference in all EF affection between three subtypes of ADHD as found by previous studies [20] and 76\% of children with combined (ADHD and LD) and this result repeated previous study findings and agrees with the body of research showing that executive dysfunction in the form of impaired response inhibition remains the most prominent cognitive theory of ADHD [21].

The present work also found that Self-restraint was not significantly affected in the children with LD affecting only $26 \%$ before excluding other comorbidities and only $20 \%$ after excluding them. While recent research suggested that executive function skills, which include monitoring and manipulating information in mind (working memory), suppressing distracting information and unwanted responses (inhibition) and flexible thinking (shifting), play a critical role in the development of mathematics proficiency, this difference might be justified by the smaller sample size of math disorder in our study.

This study showed a significant association between self -restraint and other psychiatric comorbidities mainly disruptive behavior disorders to be affected in $87 \%$ of children then epilepsy to be affected in $78 \%$ of children, and mood and anxiety disorders nocturnal enuresis to be affected in $68 \%$ and $66 \%$ respectively, this finding was similar to a study showing that oppositional defiant disorder (ODD)/

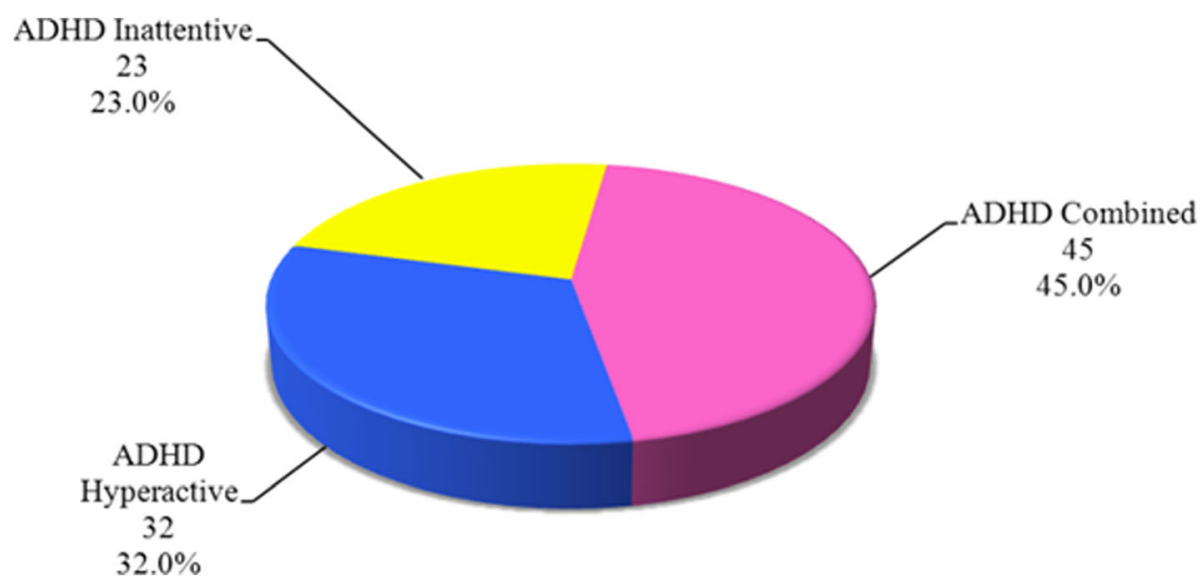

Fig. 1 Distribution of ADHD subtypes in group I 


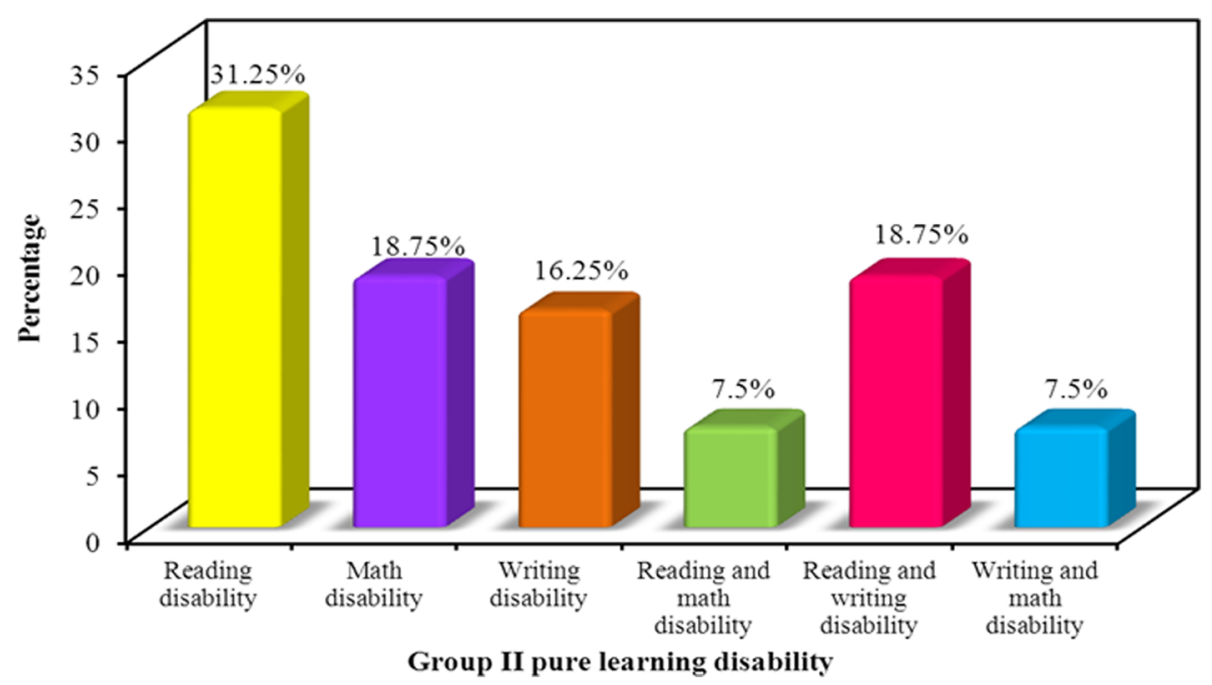

Fig. 2 Learning disorders subtypes among group II

conduct (CD) but not ADHD was related to hot EF based on increased risky decision-making in the Iowa Gambling Task. ODD/CD was also independently related to aspects of cool EF independently of ADHD, namely slower speeds of inhibitory responding and increased intra-subject variability [22].

\section{Self-motivation EF}

The present work showed that self-motivation was significantly affected in the three groups affecting $73 \%$ of the combined group, $60 \%$ of the children with ADHD, and $57.5 \%$ of children with LD.

Male sex was a significant risk factor for selfmotivation executive dysfunction $(\mathrm{OR}=0.3$, CI $0.1-$ 0.8 ), opposite to our finding. An Egyptian study by Amer et al. [23] showed that no robust differences in EF can be attributed solely to sex and that reading and metacognitive reading dysfunctions showed no gender difference; this difference can be explained by different sample size (60), different methodology using

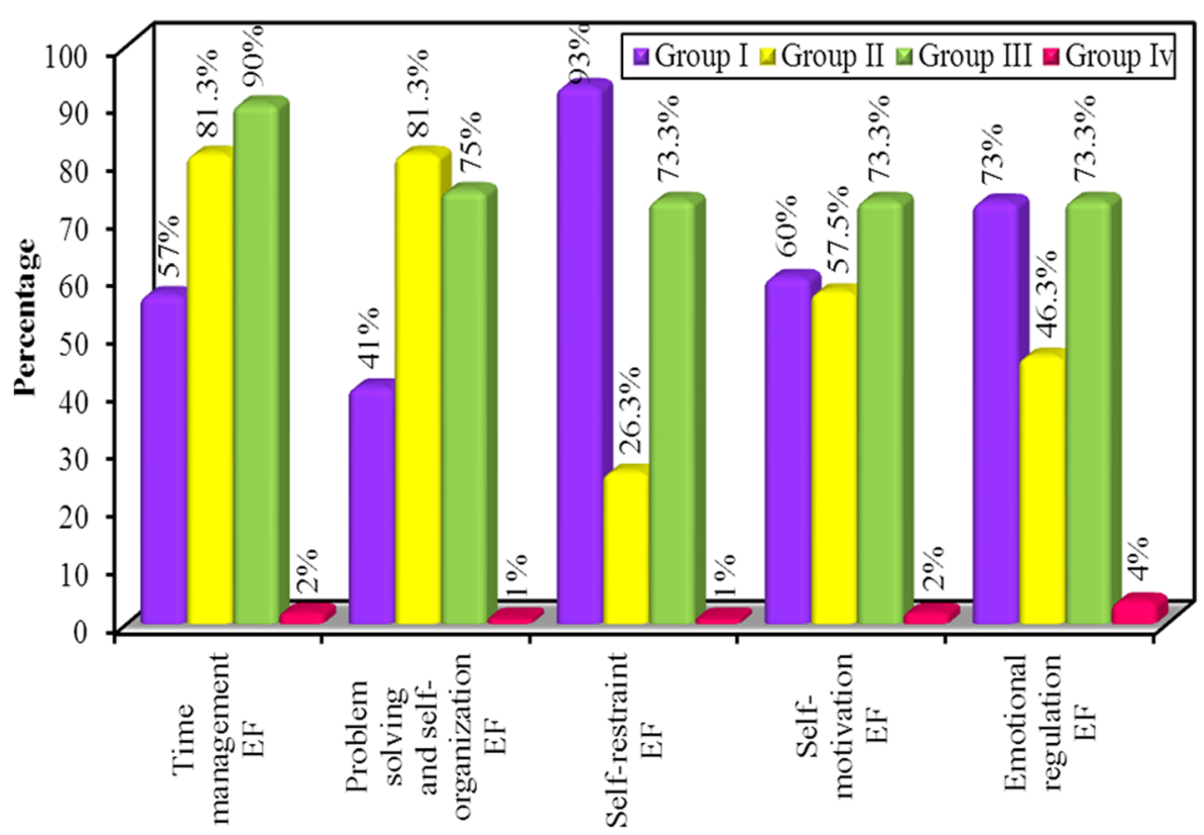

Fig. 3 Comparison between the different studied groups according to executive dyfunctions 
Wisconsin Card Sorting Test (WCST) and also that most of our sample were of the male gender.

\section{Emotion regulation EF}

The present study showed that emotion regulation was significantly affected in children with ADHD and children with combined ADHD and LD group affecting 73\% of each; this finding might explain the emotional liability symptom associated with ADHD. One study [24] showed that $80 \%$ or more of adults with ADHD report significant levels of emotional liability, often severe, and causing impairments beyond that accounted for by inattention, hyperactivity or impulsivity and drug treatments for ADHD have all been shown to improve symptoms of emotional liability.

Moreover emotion regulation was significantly related to other psychiatric comorbidities which was found to be a risk factor for emotion regulation executive dysfunction $(\mathrm{OR}=12$, CI 3-46), this came as an answer for Surman's question; Is Emotion liability in Adult ADHD due to Comorbidity? But could not answer it due to limited assessment of comorbidity contribution to emotional symptoms to date [25]. We assume based on the results of our study that the answer is Yes, as the emotion regulation executive dysfunction dropped after exclusion of children with other psychiatric comorbidities to be affecting only $37 \%$ of ADHD only group and $30 \%$ of the combined group.

The psychiatric comorbidity which was most significantly affecting this EF was disruptive behavior disorders ( including ODD and Conduct disorder) to be present in $98 \%$ of them followed by mood and anxiety disorders affecting $92 \%$ of them then epilepsy affecting $89 \%$ of them and lastly those with history of (nocturnal enuresis or language delay) affecting $79 \%$ of them. Also some studies concluded that major depressive disorder (MDD) has been associated with executive dysfunction and related abnormal prefrontal ability while other others showed that the status of EF in anxiety disorders and in comorbid depression and anxiety remain unclear [26].

\section{Limitations of the study}

The executive function assessment depended solely on parents reports using the Barkley Deficits in Executive Functioning Scale-Children and Adolescents (BDEFS-CA).

\section{Conclusion}

Results support our primary hypothesis in finding children with pure ADHD or pure learning disorders or both combined to exhibit more executive dysfunction than children of the control group.

Group I (ADHD GROUP) with its three sub types separately (inattentive, hyperactive and combined) showed significant relation to self-restraint executive dysfunction followed by emotion regulation executive dysfunction while in group II (LEARNING DISORDER GROUP) problem solving followed by time management showed to be significantly dysfunctional. It was found that recurrent accidents are significantly related to time management executive dysfunction. Therefore, EF should be assessed and managed for improving children welfare.

\section{Abbreviations}

ADHD: Attention deficit hyperactivity disorder; BDEFS: Barkley Deficits in Executive Functioning Scale; BDEFS-CA: Barkley Deficits in Executive Functioning Scale-Children and Adolescents; DSM IV: Diagnostic and Statistical Manual IV; EF: Executive functions; ICD 10: International Statistical Classification of Diseases and Related Health Problems; IQ: Intelligence quotient; LD: Learning disabilities; MRI: Magnetic resonance imaging; SCWT: Stroop Color Word Test; SLD: Specific learning disabilities; TMT: Trail making test; WCST: Wisconsin Card Sorting Test

\section{Acknowledgements}

We would like to express our gratitude to the whole staff of Alexandria University clinic for being cooperative with the research team.

\section{Consent for publications}

All authors are accepting publications.

\section{Authors' contributions}

HA: corresponding author as mentioned in the first page of this manuscript. She revised the work and she attributed to the conception of this work and interpretation of data. SG: She played an important role in the conception of this work and study design also in interpretation of data. AM: played a major role in the acquisition of data and she drafted the work. All authors have read and approved the manuscript.

Funding

This study was not funded by any organizations nor individuals.

Availability of data and materials

All data were accessible by the Internet as shown in details of references section.

\section{Ethics approval and consent to participate}

The approval of the Ethical Committee of Alexandria University was obtained and all children referred with ADHD alone, SLD alone, or with both, and fulfilling the inclusion criteria were recruited for psychiatric interview. Ethics committee reference number: not applicable

Informed verbal consent and ascents were taken from child parents because some parents are illiterate and ethical committee of Alexandria university approved this

\section{Competing interests}

There is no conflict of interests.

Received: 2 June 2020 Accepted: 27 October 2020

Published online: 11 November 2020

\section{References}

1. Biederman J, Petty CR, Fried R, Black S, Faneuil A, Doyle AE et al (2008) Discordance between psychometric testing and questionnaire-based definitions of executive function deficits in individuals with ADHD. J Atten Disord 12(1):92-102

2. Seidman LJ, Biederman J, Monuteaux MC, Doyle AE, Faraone SV (2001) Learning disabilities and executive dysfunction in boys with attentiondeficit/hyperactivity disorder. Neuropsychology 15(4):544-556

3. Shah N, Bhat T (2009) Clinical practice guidelines for the specific learning disorders. Indian J Psychiatry 51:68-95

4. Pennington BF, Ozonoff S (1996) Executive functions and developmental psychopathology. J Child Psychol Psychiatry 37(1):51-87

5. Schuchardt K, Maehler C, Hasselhorn M (2008) Working memory deficits in children with specific learning disorders. J Learn Disabil 41(6):514-523

6. Cartwright KB (2012) Insights From Cognitive Neuroscience: The Importance of Executive Function for Early Reading Development and Education. Early Educ Dev 23(1):24-36 
7. Cragg L, Gilmore C (2014) Skills underlying mathematics: The role of executive function in the development of mathematics proficiency. Trends Neurosci Educ. https://doi.org/10.1016/j.tine.2013.12.001

8. Graham S, Harris KR, Olinghouse N. Addressing Executive Function Problems in Writing An Example from the Self-Regulated Strategy Development Model. 2007.

9. Kaufman J, Birmaher B, Brent D et al (1997) Schedule for Affective Disorders and Schizophrenia for School-Age Children-Present and Lifetime Version (KSADS-PL): Initial Reliability and Validity Data. J Am Acad Child Adolesc Psychiatry. 36(7):980-988. https://doi.org/10.1097/00004583-199707000-00021

10. Coolican J, Bryson SE, Zwaigenbaum L (2008) Brief Report: Data on the StanfordBinet Intelligence Scales (5th ed.) in Children with Autism Spectrum Disorder. J Autism Dev Disord. 38(1):190-197. https://doi.org/10.1007/s10803-007-0368-2

11. Conners CK, Sitarenios G, Parker JD, Epstein JN. The revised Conners' Parent Rating Scale (CPRS-R): factor structure, reliability, and criterion validity. J Abnorm Child Psychol. 1998;26(4):257-268. http://www.ncbi.nlm.nih.gov/ pubmed/9700518. Accessed 9 April 2018.

12. Barkley RA. Barkley Deficits in Executive Functioning Scale--Children and Adolescents (BDEFS-CA). Guilford Press; 2012. https://www.guilford.com/ books/Barkley-Deficits-Executive-Functioning-Scale-Children-AdolescentsBDEFS/Russell-Barkley/9781462503940. Accessed 26 Feb 2018.

13. Sharfi K, Rosenblum S (2016) Executive Functions, Time Organization and Quality of Life among Adults with Learning Disabilities. PLoS One. 11(12): e0166939. https://doi.org/10.1371/journal.pone.0166939

14. Hosenbocus S, Chahal R. A review of executive function deficits and pharmacological management in children and adolescents. J Can Acad Child Adolesc Psychiatry. 2012;21(3):223-229. http://www.ncbi.nlm.nih.gov/ pubmed/22876270. Accessed 11 Feb 2018.

15. Mccann SJ. EXECUTIVE FUNCTIONS IN CHILDREN WTH READING DISABILTY. 2007. http:// ufdcimages.uffib.uff.edu/J/E0/02/01/07/00001/mccann_s.pdf. Accessed 17 Feb 2018.

16. Modi AC, Vannest J, Combs A, Turnier L, Wade SL (2018) Pattern of executive functioning in adolescents with epilepsy: A multimethod measurement approach. Epilepsy Behav. 80:5-10. https://doi.org/10.1016/J.YEBEH.2017.12.021

17. Risse GL (2006) Cognitive Outcomes in Patients with Frontal Lobe Epilepsy. Epilepsia. 47(s2):87-89. https://doi.org/10.1111/j.1528-1167.2006.00699.x

18. Witt J-A, Helmstaedter C (2012) Should cognition be screened in new-onset epilepsies? A study in 247 untreated patients. J Neurol. 259(8):1727-1731. https://doi.org/10.1007/s00415-012-6526-2

19. Black LC, Schefft BK, Howe SR, Szaflarski JP, Yeh H, Privitera MD (2010) The effect of seizures on working memory and executive functioning performance. Epilepsy Behav. 17(3):412-419. https://doi.org/10.1016/j.yebeh.2010.01.006

20. Aly HY, Effat SMA, Azb HM, Abd Elsamei AM (2015) Executive functions among Egyptian children with attention deficit hyperactivity disorder and reading disabilities. Middle East Curr Psychiatry. 22(2):97-106. https://doi. org/10.1097/01.XME.0000461749.64397.af

21. Roth RM, Saykin AJ (2004) Executive dysfunction in attention-deficit/ hyperactivity disorder: cognitive and neuroimaging findings. Psychiatr Clin North Am. 27(1):83-96. https://doi.org/10.1016/S0193-953X(03)00112-6

22. Hobson CW, Scott S, Rubia K (2011) Investigation of cool and hot executive function in ODD/CD independently of ADHD. J Child Psychol Psychiatry. 52(10):1035-1043. https://doi.org/10.1111/j.1469-7610.2011.02454.x

23. Amer D, Refaat O, Emad-Eldin M, Roufael R, El-Bakry A (2012) Gender differences in executive functions and reading abilities in children with attention deficit hyperactivity disorder. Egypt J Psychiatry. 33(2):63. https:// doi.org/10.7123/01.EJP.0000413587.34899.c5

24. Sobanski E, Banaschewski T, Asherson P et al (2010) Emotional lability in children and adolescents with attention deficit/hyperactivity disorder (ADHD): clinical correlates and familial prevalence. J Child Psychol Psychiatry. 51(8):915-923. https://doi.org/10.1111/j.1469-7610.2010.02217x

25. Surman CB. Paying Attention to Emotion in ADHD Nosological History of Emotional Symptoms in Attention Deficit Disorders Utah Criteria for Adult ADHD: Core traits: \&quot; affective lability \&quot; \&quot; hot temper \&quot; \&quot; stress intolerance \&quot; Studies of Emotion in Adult ADHD Deficient Emotional Regulation (DESR). 1989. http://www.chadd.org/portals/0/pdfs/fc9.pdf. Accessed 25 Feb 2018.

26. van Tol MJ, van der Wee NJA, Demenescu LR et al (2011) Functional MR correlates of visuospatial planning in out-patient depression and anxiety. Acta Psychiatr Scand. 124(4):273-284. https://doi.org/10.1111/j.1600-0447.2011.0170

\section{Publisher's Note}

Springer Nature remains neutral with regard to jurisdictional claims in published maps and institutional affiliations.

\section{Submit your manuscript to a SpringerOpen ${ }^{\circ}$ journal and benefit from:}

- Convenient online submission

- Rigorous peer review

- Open access: articles freely available online

- High visibility within the field

- Retaining the copyright to your article

Submit your next manuscript at $\boldsymbol{\nabla}$ springeropen.com 